\title{
In vivo antidiabetic activity of aqueous extract of Artemisia argyi (Chinese mugwort) in alloxan-induced diabetic rats
}

\author{
Xinliang $\mathbf{W u}^{1}$, Junxue Zhuang ${ }^{1}$, Zixia Bai ${ }^{1}$, Daliang Guo ${ }^{2 *}$ \\ ${ }^{1}$ Department of Pharmacy, Tianjin Baodi Hospital, Baodi Clinical College of Tianjin Medical University, Tianjin 301800, ${ }^{2}$ College \\ of Traditional Chinese Medicine, Tianjin University of Traditional Chinese Medicine, Tianjin 301617, China \\ *For correspondence: Email: 13920632603@126.com; Tel/Fax: 0086-022-59596221
}

\begin{abstract}
Purpose: To determine the antidiabetic, antioxidant and anti-hyperlipidemic effects of aqueous leaf extract of Artemisia argyi (Asteraceae) in alloxan ( $A L X)$-induced diabetic rats.

Experimental: Soxhlet apparatus was packed with grinded leaves of A. Argyi and subjected to extraction by double distillation using water as running solvent for $4-5 \mathrm{~h}$. Male albino Wistar rats weighing $150 \pm 10 \mathrm{~g}$ were used in this study. Diabetes was induced in overnight-fasted rats via intraperitoneal administration of freshly prepared $10 \%$ alloxan solution at a dose of $186.9 \mathrm{mg} / \mathrm{kg}$. Serum glucose (Glc), high-density lipoprotein cholesterol (HDL-c), triglycerides (TGs) and total cholesterol (TC) were evaluated using Randox assay kits. Serum reduced glutathione (GSH) was assayed using a slight modification of a previously reproted procedure, while histological examination was carried out microscopically after hematoxylin and eosin staining.

Results: Oral administration of aqueous extract of Artemisia argyi significantly reduced ALX-induced increases in glycosylated hemoglobin and blood glucose, but significantly increased total protein, hemoglobin, insulin, and C-peptide levels $(p<0.05)$. Administration of the extract also led to a significant upsurge in non-enzymic antioxidants i.e. ceruloplasmin, GSH, vitamin $E$ and vitamin $C$. The extract produced a hypolipidemic effect by significantly reducing total cholesterol (TC) and serum TGs. The hypoglycemic and hypolipidemic effects of the extract were dose-dependent $(p<0.05)$. Histological examination of the pancreas revealed that the extract protected the integrity of beta cells in ALXinduced diabetic rats.

Conclusion: These results indicate the beneficial effects of Artemisia argyi against diabetes mellitus. Thus, Artemisia argyi may be useful in the management of diabetes mellitus.
\end{abstract}

Keywords: Artemisia argyi, Antidiabetic, Glutathione, Histopathology, Antioxidant

\begin{abstract}
This is an Open Access article that uses a fund-ing model which does not charge readers or their institutions for access and distributed under the terms of the Creative Commons Attribution License (http://creativecommons.org/licenses/by/4.0) and the Budapest Open Access Initiative (http://www.budapestopenaccessinitiative.org/read), which permit unrestricted use, distribution, and reproduction in any medium, provided the original work is properly credited.

Tropical Journal of Pharmaceutical Research is indexed by Science Citation Index (SciSearch), Scopus, International Pharmaceutical Abstract, Chemical Abstracts, Embase, Index Copernicus, EBSCO, African Index Medicus, JournalSeek, Journal Citation Reports/Science Edition, Directory of Open Access Journals (DOAJ), African Journal Online, Bioline International, Open-J-Gate and Pharmacy Abstracts
\end{abstract}

\section{INTRODUCTION}

The existence of herbal medicine dates back to the era of the first human beings on the face of earth. Nowadays, it became important to study natural products for their immense richness in bioactive compounds that can be used as lead molecules in drug discovery. Traditional medicine is being extensively studied by scientists across the globe. It constitutes a vital source of therapeutic principles with respect to animal parts, herbs, and inorganic materials [1]. 
Artemisia argyi is an important medicinal herb popularly known as Chinese mugwort. Since time immemorial, several medicines used worldwide have been derived from herbs belonging to Artemisia argyi [2]. In Japan, China and Korea, $A$. princeps and $A$. argyi are incorporated in folk or traditional medicine for treating inflammation, abdominal pain, uterine hemorrhage and dysmenorrhea [3]. "Aiye" is the local name for $A$. argyi in China, and it grows as a herbaceous perennial herb. The plant parts and chemical components extracted from $A$. princeps have been shown to possess marked pharmacological effects such as anti-inflammatory, antidiabetic, anticoagulant, antifungal, and anti-tumor properties [4-9]. Several studies have been directed towards identification of the phytoconstituents of $A$. argyi. Ninety-six volatile constituents have been identified from the leaves of $A$. argyi. These include a-thujene, 1,8-cineole, camphor and artemisia alcohol [10]. Moreover, nearly 50volatile constituents have been identified from $A$. argyi flowers, and it is believed that the flowers may be just as therapeutically effective as using the leaves. Although several traditional uses of this plant have been experimentally validated, there exist no scientific confirmed reports regarding its anti-diabetic properties. Therefore, the present study was aimed at investigating the antidiabetic effect of $A$. argyi.

Diabetes mellitus (DM) is a hazardous pathological condition which results in metabolic disturbances and non-physiological alterations in several tissues, with oxidative stress playing an essential part in the disease development. Diabetes mellitus results in vascular problems that lead to considerable number of human deaths. Globally, there have been significant upsurge in diabetes patients in the past few decades, most likely due to sedentary life styles, consumption of energy-rich diets, increase in ageing populations, and obesity [11].

There are at present $150-300$ million cases of diabetes mellitus worldwide, but $\mathrm{WHO}$ has predicted a two-fold increase in diabetes cases by 2025 [12]. The available blood glucose lowering agents and dietary measures only partially correct the multiple metabolic defects associated with non-insulin dependent DM (NIDDM) with insulin resistance remaining relatively unresponsive to treatment. Hypoglycemia and secondary failure are common problems associated with currently available sulphonyl ureas. Therefore, there has been a focus on development of newer hypoglycemic agents that could address these limitations.
The present study was carried out to investigate the antihyperglycemic, antioxidant and antihyperlipidemic potential of $A$. argyi (aqueous extract) in diabetic rats.

\section{EXPERIMENTAL}

\section{Collection of plant material and extract preparation}

The aerial parts (leaves) of the herb $A$. argyi were washed in fast flowing tap water to eliminate surface dirt. Then, the plant material was dried to remove moisture, followed by cutting and grinding to powder with the help of a mechanical blender. Thereafter, the powdered material was packed into a Soxhlet apparatus and subjected to extraction with double distilled water as running solvent for $4-5 \mathrm{~h}$. The extract was then heated to dryness, and final extract yield was quantified (16.5\% yield). The dry extract was kept at $4{ }^{\circ} \mathrm{C}$ prior to use.

\section{Chemicals and reagents}

All the chemicals used in this study were of analytical grade and were acquired from Sigma Chemicals, St Louis, USA.

\section{Experimental animals}

The male albino Wistar rats used in this investigation were allowed free access to pellet diet and water. The animals were maintained within a clean environment with a 12-h day/12-h dark photoperiod at temperatures ranging from 26 to $30^{\circ} \mathrm{C}$. Approval for the experimental protocol used was received from the institutional animal ethical committee of Tianjin Baodi Hospital (approval no. TXY6411343) and followed the guidelines of Care and Use of Laboratory Animals [13].

\section{Induction of hyperglycemia}

Diabetes was induced in overnight-fasted rats through infusion of freshly prepared $10 \%$ alloxan (ALX) solution at a dose of $186.9 \mathrm{mg} / \mathrm{kg}$. The control animals were injected with normal physiological saline. Subsequently, blood was collected from overnight-fasted rats via sinocular puncture after $72 \mathrm{~h}$ of injection. Rats that showed minimum serum glucose levels greater than 270 $\mathrm{mg} / \mathrm{dL}$ were used for subsequent investigations.

The rats were randomly divided into five groups, with 10 animals/group: 3 diabetic groups and 2control groups. Two of the diabetic animal groups were given aqueous extract of $A$. argyi at doses of 100 and $200 \mathrm{mg} / \mathrm{kg}$ body weight daily. 
The extract was administered orally in the form of suspension in Tween 80 (4\%). Rats in the third group served as diabetic control (administered physiological saline only). One of the control groups received extract at a dose of $200 \mathrm{mg} / \mathrm{kg}$ body weight, while the other was kept untreated and given physiological saline only.

After two months of exposure, the rats were euthanized for sample collection, and the samples were preserved at $-70{ }^{\circ} \mathrm{C}$ until use. At $12 \mathrm{~h}$ after the administration of the last dose, blood pressure (BP) of each rat was monitored, and then the rats were anesthetized. Blood samples of each animal were withdrawn via sinocular puncture at 0,30 and 60 days. The blood samples were permitted to clot for $1 \mathrm{~h}$ at $25{ }^{\circ} \mathrm{C}$. Subsequently, the resultant serum samples were kept at $-70{ }^{\circ} \mathrm{C}$ until used for various biochemical estimations.

\section{Biochemical analysis}

Serum glucose (Glc), HDL-c, TGs and TC were determined as per manufacturer's instructions using Randox assay kits (Randox Laboratories Ltd, United Kingdom). Friedewald equation was used to determine LDL-c. Rat insulin kit (Mercodia, Uppsala, Sweden) was used to determine C-peptide and insulin levels through enzyme linked immunosorbent assay (ELISA). Total hemoglobin, glycosylated hemoglobin and total proteins were estimated using methods described previously [14].

\section{Evaluation of reduced glutathione (GSH)}

Reduced form of glutathione (GSH) in serum was measured with a slight modification of the procedure described previously [15]. In essence, $5 \%$ trichloroacetic acid $(2.0 \mathrm{~mL})$ was mixed with $0.5 \mathrm{ml}$ of serum in a centrifuge, and $1 \mathrm{~mL}$ of supernatant was collected. Then, $0.5 \mathrm{~mL}$ of Ellman's reagent and $3 \mathrm{~mL}$ of phosphate buffer were added to the supernatant. The colored sample generated was read spectroscopically at a wavelength of $412 \mathrm{~nm}$.

\section{Determination of vitamin $\mathrm{E}$ and vitamin $\mathrm{C}$ levels}

The levels of vitamin $E$ and vitamin $C$ in serum were measured using the method as described previously $[15,16]$.

\section{Histopathological investigation of pancreas}

Thin sections of rat pancreas were fixed with 4 $\mathrm{g} / \mathrm{L}$ formaldehyde, followed by paraffinization. Thereafter,the fixed sections were stained using
H\&E. Histopathological examination was done independently by two pathologists. The pancreatic lesions were recorded as described previously [17]. Score 0 depicted normal volume and population of islets cells; score Idepicted minor injury showing swellingand reduced number of islet cells; score II depicted moderate injury (i.e. moderate decrease in number of islet cells and swelling of islet cells); score III depicted obvious injury marked by clear reduction in islet cell number and pancreatic hyperplasia, while score IV implied severe injury depicting minimum number and extreme hyperplasia.

\section{Statistical analysis}

Data are presented as mean \pm SD. Statistical analysis was doneusing one way ANOVA and Duncan's multiple range test with SPSS software (version 9.05). Values ofpless than 0.05 were considered indicative of statisticallysignificant differences.

\section{RESULTS}

\section{Effect of aqueous extract of $A$. argyi on blood glucose levels}

Fasting serum glucose level of diabetic control group was elevated to $23.71 \pm 1.98 \mathrm{mmol} / \mathrm{L}$ in rats administered the higher extract dose for 60 days, relative to normal control group (3.84 \pm 0.30 $\mathrm{mmol} / \mathrm{L})$. Administration of the extract dose of $100 \mathrm{mg} / \mathrm{kg}$ to normal rats did not affect blood glucose levels, as shown in Figure 1. At a dose of $200 \mathrm{mg} / \mathrm{kg}$, the extract produced higher decreases in blood glucose levels of diabetic rats than at a dose of $100 \mathrm{mg} / \mathrm{kg}$.

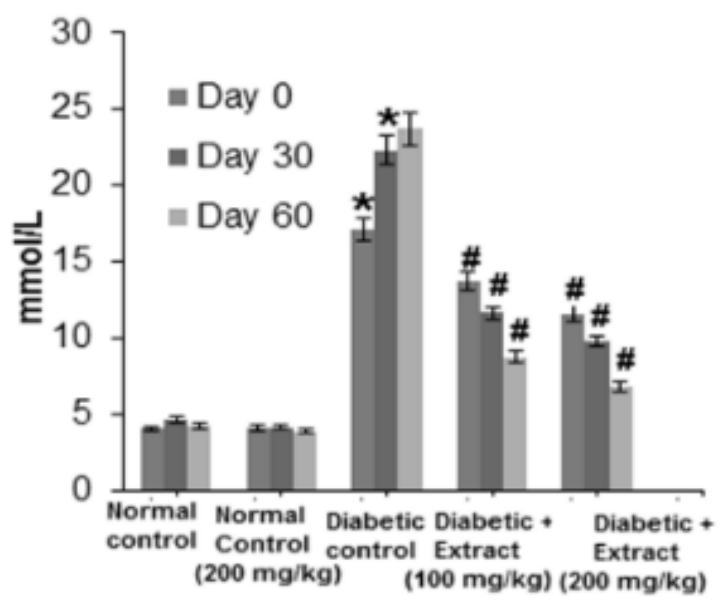

Figure 1: Effect of Artemisia argyi aqueous leaf extract on plasma glucose levels $(\mathrm{mmol} / \mathrm{L})$ of diabetic and normal rats after different time intervals viz day 0 , day 30 and day $60 ;{ }^{*} p<0.5$ vs normal control; ${ }^{*} p<$ 0.05 vs diabetic control 
Effect of aqueous extract of $A$. argyi on GSH, vitamins $C$ and $E$ levels

The influence of the extract at two doses (100 and $200 \mathrm{mg} / \mathrm{kg}$ ) on non-enzymatic antioxidant levels in diabetic and normal rats are presented in Figure 2. The levels of GSH, vitamins $\mathrm{C}$ and $\mathrm{E}$ were significantly decreased in diabetic controls, when compared to normal rats. The extract dosedependently enhanced the levels of GSH, vitamin $\mathrm{C}$ and vitamin $\mathrm{E}$ in diabetic rats, relative to diabetic controls.

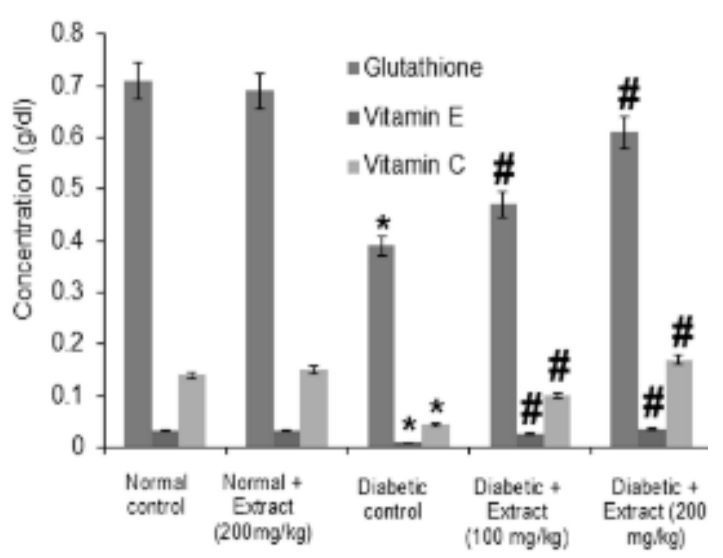

Figure 2: Effect of $A$. argyi aqueous extract on vitamin $\mathrm{C}$ and vitamin $\mathrm{E}$, and plasma glutathione. Data are mean \pm S.D. $(n=10) ;{ }^{*} p<0.5$ vs normal control; ${ }^{*} p<$ 0.05 vs diabetic control

\section{Effect of extract on insulin and other serum proteins}

Significant reductions in the concentrations of total protein, hemoglobin, insulin, and C-peptide, and enhancement in the glycosylated hemoglobin were seen in diabetic rats, relative to normal control rats (Figure 3 and Figure 4). On administration of the extract doses to diabetic rats, there were dose-dependent enhancements in these values at both doses. Marked improvements in serum insulin, total proteins, Cpeptide, and total hemoglobin, and decreases in glycosylated hemoglobin, when compared to diabetic control rats. These changes were dosedependent.

\section{Effect of extract of TGs and TC}

Changes in TG and total cholesterol levels after 2 months of study are shown in Figure 5 and Figure 6. It was observed that TG level was markedly elevated in the diabetic rats (Figure5). However, the extract significantly decreased TG levels in diabetic and control rats at both test doses after 30 and 60 days of treatment.
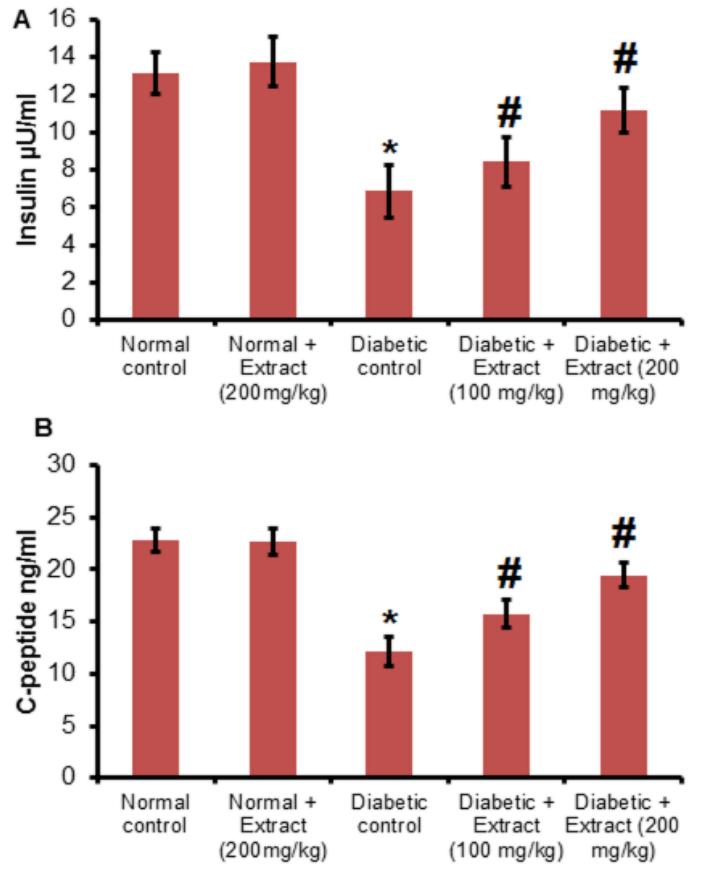

Figure 3: Effect of A.argyi on (A) insulin, and (B) Cpeptide levels at indicated doses in normal and diabetic rats. Each value is mean \pm S.D. $(n=10)$; ${ }^{*} p<$ 0.5 vs normal control; ${ }^{\#} p<0.05$ vs diabetic control
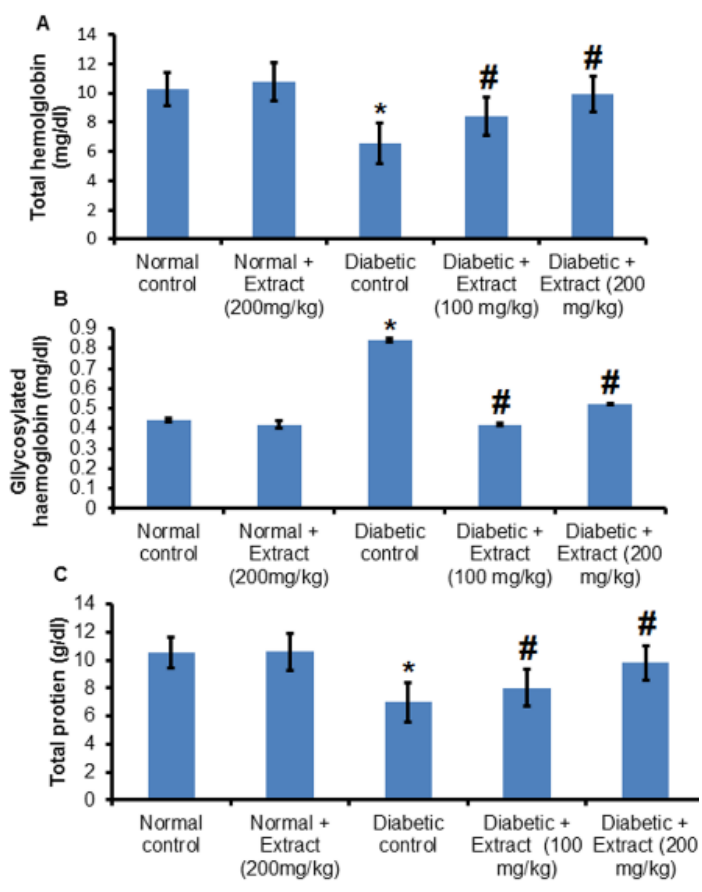

Figure 4: Effect of $A$. argyion (A) total hemoglobin, (B) glycosylated hemoglobin and $(C)$ total protein levels in normal and diabetic rats. Each value is mean \pm SD $(n=$ 10) ${ }^{*} p<0.5$ vs normal control; ${ }^{\#} p<0.05$ vs diabetic control 


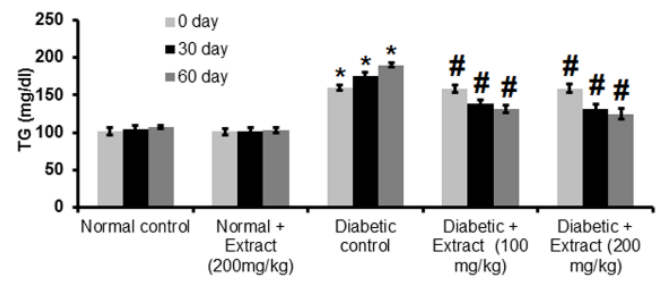

Figure 5: Effect of $A$. argyi extract on serum TG levels in diabetic and normal rats at indicated doses. Each data entry is mean + SD $(n=10) ;{ }^{*} p<0.5$ vs normal control; ${ }^{\#} p<0.05 \mathrm{vs}$ diabetic control

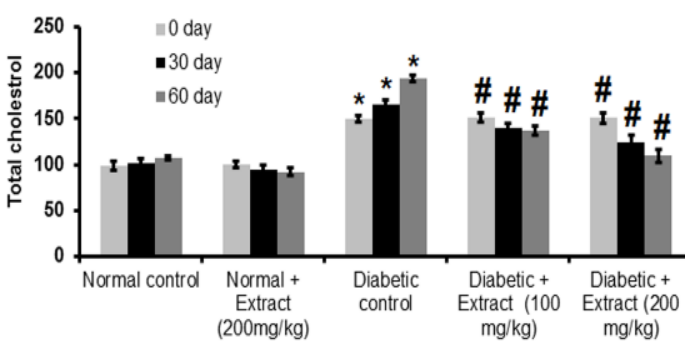

Figure 6: Effect of $A$. argyi extract on serum TC levels at given doses. Each data entry is mean $+S D(n=10)$ ${ }^{*} p<0.5$ vs normal control; ${ }^{\#} p<0.05$ vs diabetic control

The results demonstrated that diabetic rats had more significant elevation in TC levels than normal rats (Figure 6). Moreover, the concentrations of TC in diabetic groups receiving the extract at two different doses were markedly decreased. No such effects were observed on cholesterol levels in the normal control rats. After 30 days of treatment, the TC lowering effect of the extract became apparent. The TC lowering effects of extract was also observed in normal control group. Increases in TC levels became apparent in diabetic rats after 60 days.

\section{Histological features}

Results from $\mathrm{H} \& \mathrm{E}$ staining revealed that vehicle (4\% Tween 80 ) administration alone did not lead to any prominent alterations in pancreatic histology throughout the study (Figure $7 \mathrm{~A}$ ). Normal mice did not show any pancreatic lesions (Figure 7 B). In contrast, ALX treatment produced marked deleterious effects on pancreatic histology, as manifested in decreased number of islets and reduction in the islet diameter. Contracted islets of Langerhans were seen in diabetic rats (Figure $7 \mathrm{C}$ ). However, the extract mitigated the lesions seen in the islets of Langerhans. The pancreatic injuries were prevented to a significant extent on administration of extract at doses of 100 and 200 $\mathrm{mg} / \mathrm{kg}$ (Figure $7 \mathrm{D}$ and $\mathrm{E}$, respectively).
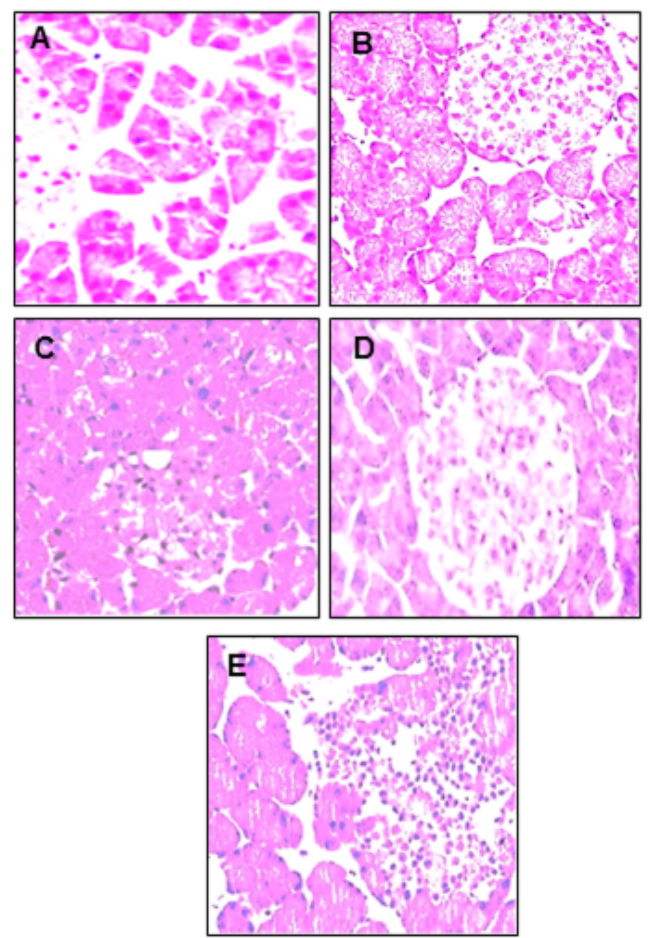

Figure 7: Histopathological changes in pancreas. (a) Normal control. (b)Normal control plus $200 \mathrm{mg} / \mathrm{Kg}$ extract. (C) Diabetic rats (D) Diabetic rats plus 100 $\mathrm{mg} / \mathrm{kg}$ extract. (D) Diabetic rats plus $200 \mathrm{mg} / \mathrm{kg}$

\section{DISCUSSION}

Natural products have been reported to possess pharmacological properties, along with low side effects. Thus, their use in different health care systems is gaining tremendous attention. Over the years, plants and plant-derived products have been used to in the treatment of several diseases and disorders in different traditional medicine systems. However, the traditional uses of only a few species have been validated scientifically. One of such herbs which are being extensively used in Chinese system of medicine is $A$. argyi [1]. The present study, therefore, is the first of its kind to investigate in vivo anti-diabetic effect of $A$. argyi.

Several investigations have suggested the active role of oxidative stress in diabetic complications [18]. Increased oxidative stress in a diabetic state is due to excess levels of free radical species and weakened antioxidant defenses [19]. Oxidative stress results in cellular adaptation or leads to cellular injury such as oxidative damage to lipids, proteins and genetic material, as well as impairment of inter- and intracellular homeostasis [20]. 
The administration of certain antioxidants in experiment an-diabetic animal models has been demonstrated to cause significant reduction in oxidative stress [21]. Moreover, A. argyi possesses antioxidant properties. Therefore, it was speculated that it may exhibit anti-diabetic effects. The results of this study indicated that administration of ALX led to significant decreases in C-peptide and insulin levels, and marked elevation in blood glucose levels. However, these changes were reversed by treatment with $A$. argyi extract. The extract produced significant free radical-scavenging potential and it decreased lipid peroxidation. Lipid peroxidation is involved in prevention of ALX-stimulated oxidative stress [22]. The extract had protective effect on $\beta$-cells, leading to enhanced secretion of insulin that ultimately lowered blood glucose levels. The raised insulin levels might be attributed to the stimulatory effect of aqueous extract of $A$. argyi on the $\beta$-cells of islets of Langerhans.

C-Peptide is synthesized during insulin biosynthesis and the two peptides are then secreted in a 1:1ratio into the circulatory system [23]. Thus, an elevation in C-peptides was accompanied by an increase in insulin secretion. This may possibly be due to regeneration of $\beta$ cells of the Langerhans. Similar effects were observed in studies carried out on Artemisia princeps inC57BL/6 mice fed a high fat diet. It was also observed that the $A$. argyi extract decreased total serum protein levels. This may be attributed to enhanced lipid peroxidation. Moreover, the decreases in serum proteins may also be due to reduced uptake of amino acids, higher conversion rate of amino acids (glycogenic) to $\mathrm{CO}_{2}$ and $\mathrm{H}_{2} \mathrm{O}$, decreased concentrations of essential amino acids, and lowered rate of protein synthesis is due to a reduction in the amount and availability of mRNA. Lowered serum protein contents have been reported in diabetic patients. The ALXinduced diabetic rats had marked elevations in serum TC and TG at $30^{\text {th }}$ and $60^{\text {th }}$ days of the study. This hypertriglyceridemia could be a consequence of either VLDL overproduction by the liver, or defective removal of TG-rich LPL from the circulation, or both.

\section{CONCLUSION}

Aqueous extract of $A$. argyi exhibits marked antihyperglycemic and antioxidant effects. Therefore, the plant has promising potential for development into a drug for management of DM. Thus, there is need for further studies on these desirable biological properties.

\section{DECLARATIONS}

\section{Conflict of interest}

No conflict of interest is associated with this work.

\section{Contribution of authors}

We declare that this work was done by the authors named in this article and all liabilities pertaining to claims relating to the content of this article will be borne by the authors. Xinliang Wu, Junxue Zhuang, Zixia Bai contributed to this work equally. Xinliang Wu, Junxue Zhuang, Zixia Bai performed all experiments together. The whole study is designed and supervised by Daliang Guo.

\section{Open Access}

This is an Open Access article that uses a funding model which does not charge readers or their institutions for access and distributed under the terms of the Creative Commons Attribution License (http://creativecommons.org/licenses/by/ 4.0) and the Budapest Open Access Initiative (http://www.budapestopenaccessinitiative.org/rea d), which permit unrestricted use, distribution, and reproduction in any medium, provided the original work is properly credited.

\section{REFERENCES}

1. DeVos P. European materia medica in historical texts: longevity of a tradition and implications for future use. $J$ Ethnopharmacol 2010; 132(1): 28-47.

2. Huang HC, Wang HF, Yih KH, Chang LZ, Chang TM. Dual bioactivities of essential oil extracted from the leaves of Artemisia argyi as an antimelanogenic versus antioxidant agent and chemical composition analysis by GC/MS. Int J Mol Sci 2012; 13(11): 14679-14697.

3. Kim CM, Shin MG, An DG, KS Lee. The Encyclopedia of Oriental Herbal Medicine, Jeongdam, Seoul, Republic of Korea, 1997.

4. Bao X, Yuan H, Wang C, Liu J, Lan M. Antitumor and immunomodulatory activities of a polysaccharide from Artemisia argyi. Carbohydr Polym 2013; 98(1): 1236-43.

5. Choi EJ, Kim GH. Antioxidant and anticancer activity of Artemisia princeps var. orientalis extract in HepG2 and Hep3B hepatocellular carcinoma cells. Chin J Cancer Res 2013; 25(5): 536.

6. Khan M, Yu B, Rasul A, Al Shawi A, Yi F, Yang H, Ma T. Jaceosidin induces apoptosis in U87 glioblastoma cells through G2/M phase arrest. Evid Based Complement Alternat Med. 2012; 2012: 703034.

7. Kim JH, Jung SH, Yang YI, Ahn JH, Cho JG, Lee KT, Baek NI, Choi JH. Artemisia leaf extract induces

Trop J Pharm Res, July 2020; 19(7): 1492 
apoptosis in human endometriotic cells through regulation of the $p 38$ and $N F K B$ pathways. $J$ ethnopharmacol 2013; 145(3): 767-775.

8. Wenqiang $G$, Shufen $L$, Ruixiang $Y$, Yanfeng $H$. Comparison of composition and antifungal activity of Artemisia argyi Levl. et Vant inflorescence essential oil extracted by hydrodistillation and supercritical carbon dioxide. Nat Prod Res 2006; 20(11): 992-998.

9. Ryu R, Jung UJ, Kim HJ, Lee W, Bae JS, Park YB, Choi MS. Anticoagulant and antiplatelet activities of artemisia princeps Pampanini and its bioactive components. Prev Nutr Food Sci 2013; 18(3): 181.

10. Pan JG, Xu ZL, Ji L. Chemical studies on essential oils from 6 Artemisia species. China journal of Chinese materia medica 1992; 17(12): 741-744.

11. World Health Organization: Diabetes mellitus. Fact sheet no. 138, 2002.

12. Karau GM, Njagi ENM, Machocho AK, Wangai LN, Kamau PN. Hypoglycemic Activity of Aqueous and Ethylacetate Leaf and Stem Bark Extracts of Pappea capensis in Alloxan-Induced Diabetic BALB/C Mice. British Journal of Pharmacology and Toxicology 2012; 3: 251-258.

13. Kastenmayer RJ, Moore RM, Bright AL, Torres-Cruz R, Elkins WR. Select agent and toxin regulations: beyond the eighth edition of the Guide for the Care and Use of Laboratory Animals. J Am Assoc Lab Anim Sci 2012; 51(3): 333-338.

14. Omaye ST. Ascorbic acid analysis. II. Determination after derivatisation with 2.2. dinitrophenylhidrazine. Selected methods for determination of ascorbic acid in animal cells tissues and fluids. Method enzymol 1979; 62: 7-8.
15. Li QG, Sun R, Gao FZ. Effect of Shen Di Jiang Tang granules on diabetic rats. China Journal of Chinese Materia Medica 2001; 26:488-90.

16. Baynes JW. Role of oxidative stress in development of complications in diabetes. Diabetes 1991;40(4):405-12.

17. Halliwell B, Gutteridge JM. Role of free radicals and catalytic metal ions in human disease: an overview. Method enzymol 1990; 186: 1-85.

18. Jakus $V$. The role of free radicals, oxidative stress and antioxidant systems in diabetic vascular disease. Bratisl Lek Listy 2000; 101(10): 541-551.

19. Sanders RA, Rauscher FM, Watkins III JB. Effects of quercetin on antioxidant defense in streptozotocin-induced diabetic rats. J Biochem Mol Toxicol 2001; 15(3): 143-9.

20. Coskun O, Kanter M, Korkmaz A, Oter S. Quercetin, a flavonoid antioxidant, prevents and protects streptozotocin-induced oxidative stress and $\beta$-cell damage in rat pancreas. Pharmacol res 2005; 51(2): 117-123.

21. Wahren J, Ekberg K, Samnegård B, Johansson BL. Cpeptide: a new potential in the treatment of diabetic nephropathy. Curr Diab Rep 2001; 1(3): 261-266.

22. Chakravarthy BK, Saroj G, Gambhir SS, Gode KD. Pancreatic beta cell regeneration-a novel antidiabetic mechanism of Pterocarpus marsupium roxb. Indian $J$ Pharmacol 1980; 12(2): 123.

23. RG A. The physiological and biochemical effects of diabetes on the balance between oxidative stress and antioxidant defense system. Med J Islamic World Acad Sci 2005; 15(1): 31-42. 